\title{
Knowledge management practice in two Australian Architecture- Engineering-Construction (AEC) companies
}

Patrick X.W. Zou (Senior Lecturer and Director Master of Construction Management Program, Faculty of the Built Environment, The University of New South Wales, Australia)

\section{ABSTRACT}

Knowledge management (KM) could be described as a management system that supports the creation, sharing and retrieving of valued information, expertise and insight within and across communities of people and related organizations using information and communication technologies and hence it is a combination of the effective application of information technology and management of human resources. KM is becoming a core competitive factor in construction operations. This paper presents the results of two case studies of KM practice in large AEC (Architecture, engineering and construction) companies through desk-top study and semistructured interviews. The results indicate that implementing KM in AEC companies leads to competitive advantages and improved decision-making, problem-solving and business performance. The results also indicated that while technology plays an important role, top management commitment, total employee involvement, performance assessment and the culture of knowledge-learning and sharing must be considered when implementing $\mathrm{KM}$. Therefore it is suggested that the implementation of KM should incorporate the company's vision, work processes, technology and culture, to improve the ability of knowledge creating, capturing, sharing, retrieving, and ultimately, to improve the company's competitive advantage, decision-making, problem solving and innovation.

Keywords: construction management, knowledge management, knowledge-sharing culture, performance assessment, AEC companies

\section{INTRODUCTION}

Knowledge may be described as the insight, experience and ability that reflects the understanding of how something works and what the future will be like and it is often categorized into two types: tacit and explicit. Knowledge management may be described as a system that supports the creating, sharing and retrieving of valued information, expertise and insight within and across communities of people and related organisations, and leads to better decision-making and improved problem solving. It is generally accepted that knowledge needs to be managed if construction businesses are to remain competitive and be responsive to the needs of their clients (Kamara et al., 2002). The ultimate outcomes of knowledge management is innovation and improved business performance. While many researchers have studied KM in other commercial sectors such as business and trade (Tiwana, 2000; Naoum, 2001; Probst, et al., 2000; Malhotra, 2000), some conducted research in relation to the construction context (Egbu, 1999; Rezgui, 2001; Kamara et al.,
2002; Zou and Lim, 2002; Fong, 2003; Chang et al., 2003; Ofori, 2003; Girmscheid and Borner, 2003; Zou et al., 2003; Siemieniuch and Sinclair, 2004).

Rezgui (2001) described that knowledge in the construction context can be classified into the three categories: Domain knowledge, organisational knowledge and project knowledge. The domain knowledge includes administrative information, standards, technical rules, product databases etc, while the organisational knowledge is company specific and is the intellectual capital of the firm which comprises knowledge about personal skills, employees' project experiences and business relationships with other stakeholders. The project knowledge includes both project records and the recorded or un-recorded memory of processes, problems and solutions. Rezgui (2001) also reviewed the information technology and state of the art of knowledge management in the construction domain, including some specific software, such as groupware systems, decision support systems and data warehouse solution to knowledge management. A specific data warehouse architecture called KMCOP which includes 6 modules - knowledge extraction, knowledge cleaning and transforming, knowledge indexing, knowledge refreshing, knowledge discovery and distribution was described in details. It is clear that Rezgui (2001) was focused on the development of IT infrastructure that facilitates KM. Rezgui (2001) concluded that IT will have an impact on managing construction knowledge and it is also important to reengineer the business process and remove culture barriers.

Kamara et al (2002) through a detailed study of current knowledge management processes in construction sector, presented a framework named CLEVER for selecting a knowledge management strategy that takes the organisational culture into consideration. This CLEVER framework was focused on the selection of an appropriate KM process for project knowledge and it includes key steps: Define KM problem, Identify 'to-be' solution, Identify critical migration paths and Select appropriate KM processes. As such the CLEVER framework includes a few components: 'Problem Definition Temple, a Knowledge Dimensions Guide, Migration Path Tools and a Generic KM Process Model'. It also provided an example on knowledge transfer including sources to be transferred, transfer target and method for transferring (either through people, software or paper). It is clear that Kamara et al (2002)'s research was focused on the KM process and contents.

However, Malhotra (2000: 14) pointed out that "... Knowledge management is based on the need for synergy between the capabilities of advanced information technologies and human creativity and innovation to realize agility demanded by emerging business environment." He also addressed that 
organizations should shift from information process to knowledge creation in which KM technologies are used to store and distribute human intelligence and experience. He then explained how information executives should rethink in relation to KM, the fundamental assumptions about business strategy, design and use of information technology, the role of senior management, organisational knowledge processes, economics of organisational assets, and organisation design for business model innovation. This means that $\mathrm{KM}$ is a combination of the application of IT and management of human resources and it is embedded into the business strategies and processes.

Siemieniuch and Sinclair (2004) argued that knowledge has a lifecycle therefore the term "knowledge lifecycle management (KLM)" was used rather than "knowledge management". They classify knowledge into technological, organisational and network three classes. Furthermore they provided a framework for organisational readiness for knowledge management. They concluded that "knowledge lifecycle management is not merely a question of buying in sophisticated knowledge elicitation and mining technologies, although these tools do have a critical role to play in the overall KLM process" and, "for an organisation to get the most added value out of the knowledge that is held within the organisation (in people's heads, in design [and construction method] databases, in processes and products etc) then it must establish an appropriate context for knowledge management" (Siemieniuch and Sinclair, 2004: 94). It is again clear that knowledge management is about IT as well as people.

Egbu et al (2004) in their final report "knowledge management for sustainable construction competitiveness" stated that "the construction industry is a knowledge based industry and the production of knowledge is vital for organisations and their project teams" (Egbu et al, 2004: 16). They further pointed out that "in construction organisations, the potential benefits of technologies for knowledge management are not fully understood" (Egbu et al, 2004: 16). Further to these, their research found that "most organisations do not have a structured approach for selection of knowledge management technologies and techniques (Egbu et al, 2004: 16)" and for those who have a formal KM system, "changing people's behaviour is cited as the biggest impediment to knowledge transfer within organisations (Egbu et al, 2004: 13)".

A comprehensive review on the literature related to the implementation of KM in construction companies could be found in Zou and Lim (2002) and they have addressed the reasons why AEC companies should implement KM: these include enhancing management roles, increasing competitive advantages, improving innovative capabilities. Zou et al (2003) pointed out that the key issues to implement KM successfully in construction firms include utilisation of information technology, integrated business processes, motivated people (include the $\mathrm{KM}$ team) and positive culture. They provided a framework for implementing KM in AEC companies. Furthermore, Zou et al (2003) conducted a questionnaire survey to the construction companies and found that while most companies were aware of $\mathrm{KM}$ and have carried out some form of KM activities, few companies were implementing $\mathrm{KM}$ as an explicit company strategy.

From the literature studies presented above, it is clear that KM has a wider domain than information management and it is about the effective management of human resources to achieve business objectives through the application of information technology and promotion of organisational knowledge sharing culture. In a knowledge management-oriented company, knowledge employees use today's advanced technologies such as electronic networking to pave the way for knowledge capture, flow, transfer and retrieve. This in turn saves time and cost of knowledge sharing irrespective of distance and physical locations. The aim of this paper is to unfold the current practice of KM implementation in major construction enterprises so that the lessons learned by these companies can be good references to others. The objectives of this paper is therefore to study the company's KM perspective, KM processes, technical and technological capability in KM, KM performance assessment and factors influencing KM implementation. This paper reports the findings of two in-depth case studies on the KM implementation approach adopted by two leading Australian construction companies.

\section{CASE STUDIES METHOD AND DESIGN}

Generally speaking, three methods are commonly used to collect data for a research: questionnaire, interview and case study. As mentioned previously, Zou et al (2003) conducted a questionnaire survey with the construction companies in Sydney region to study the current practice of $\mathrm{KM}$ in construction firms and their research findings were that while many companies were aware of the term KM and practiced it informally, only a few companies have actually established formal strategies to implement KM. With this in mind, this research is to conduct an in-depth study on the practices of those companies who have a formal strategy to implement KM. In other words, the cases selected were identified through the method of opportunistic sampling. Opportunistic sampling means that the researcher takes advantages of opportunities during the data collection to select important cases (Johnson and Christensen, 2000). The selected cases may be critical, negative, extreme or typical. In this study, the two cases were selected based on their positive responses to the survey questionnaire and the fact that they have shown a strong interest in the topic as well have given helpful suggestions in the questionnaire (see Zou et al 2003 for details of questionnaire survey).

The case studies were developed on a linear-analytical structure in an attempt to obtain full details of the construction companies' KM implementation approach. The information presented in this paper was collected mainly through a desktop study and semi-structured interviews. During the interview, each respondent was asked for information, opinions, and insights based on an identical set of questions. This approach increases the comparability of survey results since all respondents answer the same questions. It also facilitates the organisation, analysis and evaluation of the information collected. The design and structure of the interview questions 
was developed based on the literature review findings as mentioned in the Introduction Section. The background of the companies interviewed was first studied, followed by an analysis of their historical narrative of the KM development. Then, the company's KM perspective, KM processes; technological capabilities; KM performance assessment and factors influencing KM implementation are all studied:

Section 1 - KM Perspective. The purpose of this section was to gain an understanding of the KM vision and objectives of the company. From these objectives, the construction company's perspectives toward KM could then be determined and, in turn, the company's approach to KM implementation identified.

Section 2 - KM Processes. The questions in this section were intended to identify the company's KM processes through its KM structure and how knowledge assets were categorised.

Section 3 - Technical Capability in KM. This section covered technical issues relating to $\mathrm{KM}$ since different companies may have different methods of implementing $\mathrm{KM}$.

Section 4 - KM Performance Assessment. This section was directed at evaluating the performance of $\mathrm{KM}$ in each company. The performance assessment of $\mathrm{KM}$ is the central issue of whether or not KM is beneficial for construction companies and is the main concern of any company contemplating the introduction of $\mathrm{KM}$.

Section 5 - Factors Influencing KM Implementation. The questions in this section were designed to capture the positive and negative factors influencing KM implementation in a construction company. The questions were aimed also at gaining additional information and insight into the practicalities of KM implementation.

The interviews were carried out with the chief knowledge officer of the company and each interview lasted about 2 hours. The following sections present the results of the case studies with a linkage to the current literature.

\section{CASE 1 - BOVIS LEND LEASE (BLL)}

Company Background and Infrastructures in Relation to KM BLL was formed in 1999, through the acquisition of the Bovis Group by Lend Lease Corporation. It is a multi-national Project Management and Construction company with global business coverage. With more than 7,000 employees in 93 offices worldwide, BLL is involved in various project management and construction delivery projects, including commercial, residential and industrial works. Besides these, the company is involved in the infrastructure sector, with particular emphasis on water, rail, airports, power, information technology and telecommunications. With the experience and expertise in the construction field, the company provides a wide range of services to their clients. These include risk management, prefeasibility and feasibility studies, master-planning, project management, process design, construction delivery, financial structuring and engineering, and development management (BLL, 2004a).
The start of KM in BLL can be traced back to early 1997 when Lend Lease invested $A \$ 8$ million in implementing a major business process re-engineering (BPR) exercise, called "Excalibur", where an external business consultant - Arthur Anderson Business Consulting - was engaged to provide consultation to their business in order to develop and improve the core business processes. The concept of KM was introduced as part of the BPR exercise. However, there was no specific KM program in place prior to that time.

"Excalibur" provided the first step in the introduction of KM into the company. At that point, it was believed that KM could be achieved through the deployment of a database system that was a repository for BLL staff to store information and knowledge. Most of the information and documents related to the business processes were housed in a database called "Merlin" (in Lend Lease Corporation), which was equipped with a variety of navigation methods and a search engine for the purposes of retrieving data and information. Employees were encouraged to submit documents to the database. All documents and information uploaded to the database were identified by their authors so that, if there were any discrepancy or changes in the documents, answers and solutions could be referred to the authors.

Prior to merging, the Bovis Group also had its own database system "Wingspan" (later renamed "Boomerang") which is a database that contained documentation on business processes, including project fact sheets, lessons learnt documents and other documents related to projects.

To date (at the time of writing this paper), both databases "Merlin" and "Boomerang", which are due to be combined into a single database - are still two separate and distinct databases. Despite the efforts of the BLL management to combine both systems and to further develop the composite system, little has been achieved due to the fact that the two systems have different platforms. (Note: Merlin is Lotus Notes-based whereas Boomerang is Microsoft application-based), and were designed to serve different purposes. Moreover, the current management team has now realised that simply providing a database does not change or improve the behaviour and attitude of their employees in respect of knowledge-sharing. Consequently, the company introduced a new knowledge-sharing program called 'ikonnect ${ }^{\mathrm{TM}}$ '.

In 2000, BLL reviewed their KM system and brainstormed improvements to this system. When management studied the strengths and weaknesses of their business processes in relation to the cultural issues, they found that they had relatively few difficulties in the matter of knowledge-sharing since the company has an engineer-based culture where, if questions were asked, there were many people willing to answer and share their expertise. Unfortunately, there was not enough active questioning occurring which meant the desire to help went untapped. In order to become one of the leading construction companies in the world, BLL believed that they needed to have a culture of people not only willing to share knowledge, but also actively asking questions and seeking new knowledge. 
ikonnect ${ }^{\mathrm{TM}}$ is a global knowledge-sharing program in BLL that helps employees to solve their problems. Employees seeking knowledge are connected with experienced people who are willing to share their insights through the ikonnect ${ }^{\mathrm{TM}}$ system. It provides a quick and easy means of accessing BLL's global expertise and insight (BLL, 2002).

\section{Knowledge Management Perspectives}

Currently, BLL has as their main KM objective to change their collective culture to an environment in which their employees have an appetite for seeking and sharing knowledge and thus support their company's vision of becoming "the number one provider of construction project management solutions in the world".

Given that BLL has more than 7,000 employees, the main challenge of their KM mission is to harness the talents, expertise and knowledge of all the employees throughout the world to achieve continuous improvement of their business activities. The priority is to completely implement ikonnect ${ }^{\mathrm{TM}}$ and further develop the system once it is successfully embedded in the company. The company has made considerable and sustained efforts to ensure that ikonnect ${ }^{\mathrm{TM}}$ is a stable and reliable system and it is now the flagship of their $\mathrm{KM}$ strategy with the primary objective of encouraging staff to seek out new knowledge.

The previous KM approaches in BLL in the form of "Excalibur" and "Boomerang" was to develop knowledge databases and encourage employees to submit documents, which led to the creation of a knowledge stock. This strategy was more towards a "supply side" model. On the other hand, the implementation of ikonnect ${ }^{\mathrm{TM}}$ is now being viewed as a "demand side" strategy, which focuses on stimulating the demand of KM in BLL.

The knowledge-sharing initiative is based on the premise that employees in BLL can make better decisions by utilising the collective knowledge of staff within the company. In particular, this should improve their decision-making processes which will in turn improve the service they deliver to their clients, and also add value to their clients' investment, as well as potentially gaining a competitive advantage in the global construction market (BLL, 2002).

The key objective with ikonnect ${ }^{\mathrm{TM}}$ is to break down the barriers that prevent employees from seeking, sharing, learning and using knowledge. As the company has its business coverage globally, the geographical limitation of an individual's networks could be overcome through the implementation of ikonnect ${ }^{\mathrm{TM}}$ (BLL, 2002).

It is believed that ikonnect ${ }^{\mathrm{TM}}$ will enhance BLL's global approach to business activity. By facilitating wider knowledge networks throughout the organization, ikonnect ${ }^{\mathrm{TM}}$ will help the company to win new work, increase client satisfaction, contribute to improved project delivery and minimize risk. But perhaps, equally importantly, it will encourage people to share what they know.
Knowledge Management Processes

The operation of ikonnect $^{\mathrm{TM}}$ is relatively simple as it does not require any new computer skills by a user. As shown in Figure 1 , the users normally contact the ikonnect $^{\mathrm{TM}}$ facilitators by using telephone, email or in person. The facilitators have been selected with enough experience to be able to respond to any type of request. Generally, the facilitators will need to understand the nature and scope of the problem asked before they can allocate somebody within their geographical region to help in providing answers to the problem. Sometimes the question will be sent to the other regional facilitators so that their network can also be accessed in order to bring a greater number of people in helping with the issue. By doing so, the questions raised in the company will help to build up the knowledge of "who knows what?" thus making it easier to solve further questions in the future (BLL, 2004b). 


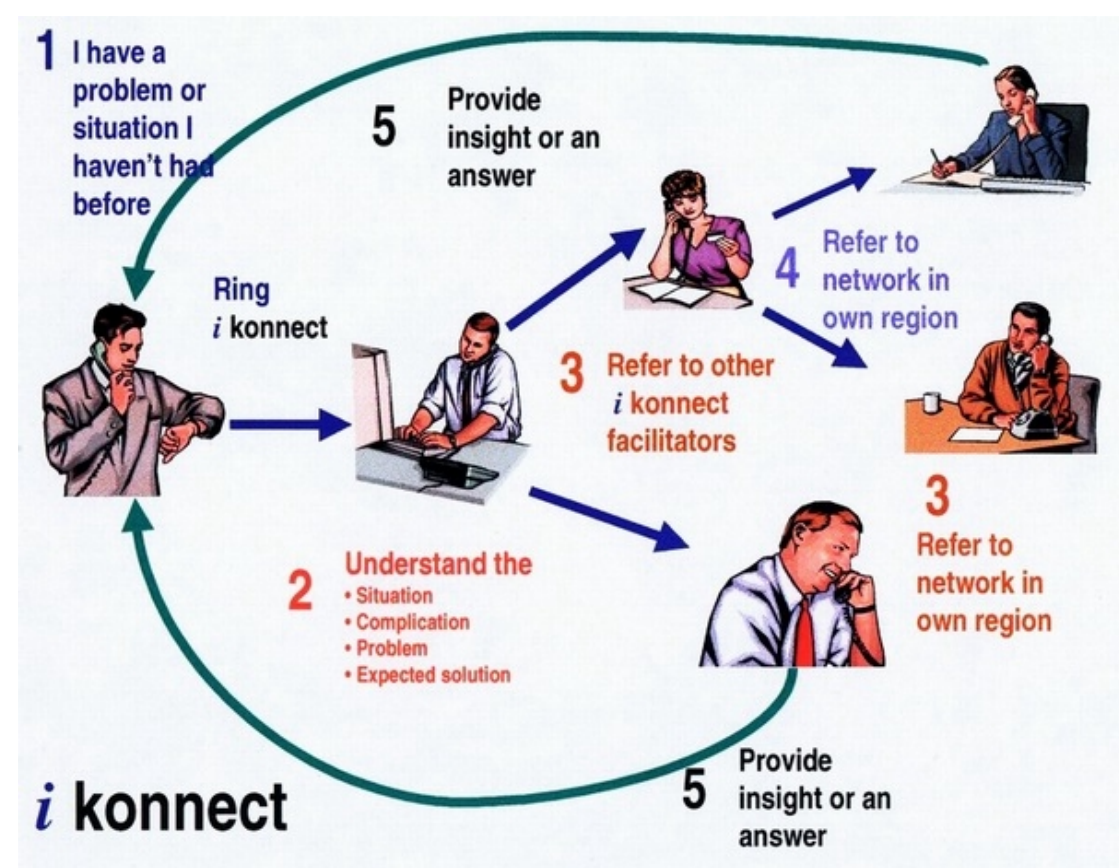

Figure 1: The operation of ikonnect ${ }^{\mathrm{TM}}$ in Bovis Lend Lease (Source: BLL 2002)

At the time of writing this paper, ikonnect ${ }^{\mathrm{TM}}$ is the "flagship" KM initiative within BLL. BLL is eager to promote the ikonnect ${ }^{\mathrm{TM}}$ program among their employees throughout the world. As such, the team designed a "briefing pack" and top management in $B L L$ used their influence by writing to regional managers to strongly encourage the adoption of the $i$ konnect $^{\mathrm{TM}}$ program. The briefing pack included the following documents: ikonnect ${ }^{\mathrm{TM}}$ Frequently Asked Questions sheet, ikonnect ${ }^{\mathrm{TM} M}$ Prompt Sheet, and ikonnect ${ }^{\mathrm{TM}}$ Newsletter have been distributed to employees in the company to make them aware of this new KM program so that more employees will involve themselves in ikonnect ${ }^{\mathrm{TM}}$.
The organisational structure for the ikonnect ${ }^{\mathrm{TM}}$ team is shown in Figure 2. This global team structure is basically organised into three main levels. The first level is the top management of BLL - the CEO and Executive Vice President for e-business and knowledge-sharing (in the United States of America). The second level is the Vice President for Global KM who also works in the United States of America. The Vice President Global Knowledge is the leader in ikonnect ${ }^{\mathrm{TM}}$ program and coordinates the knowledge managers in the company. The third level is the ikonnect ${ }^{\mathrm{TM}}$ facilitators and knowledge managers (who also play some role as facilitators), Global markets business and BP alliance.

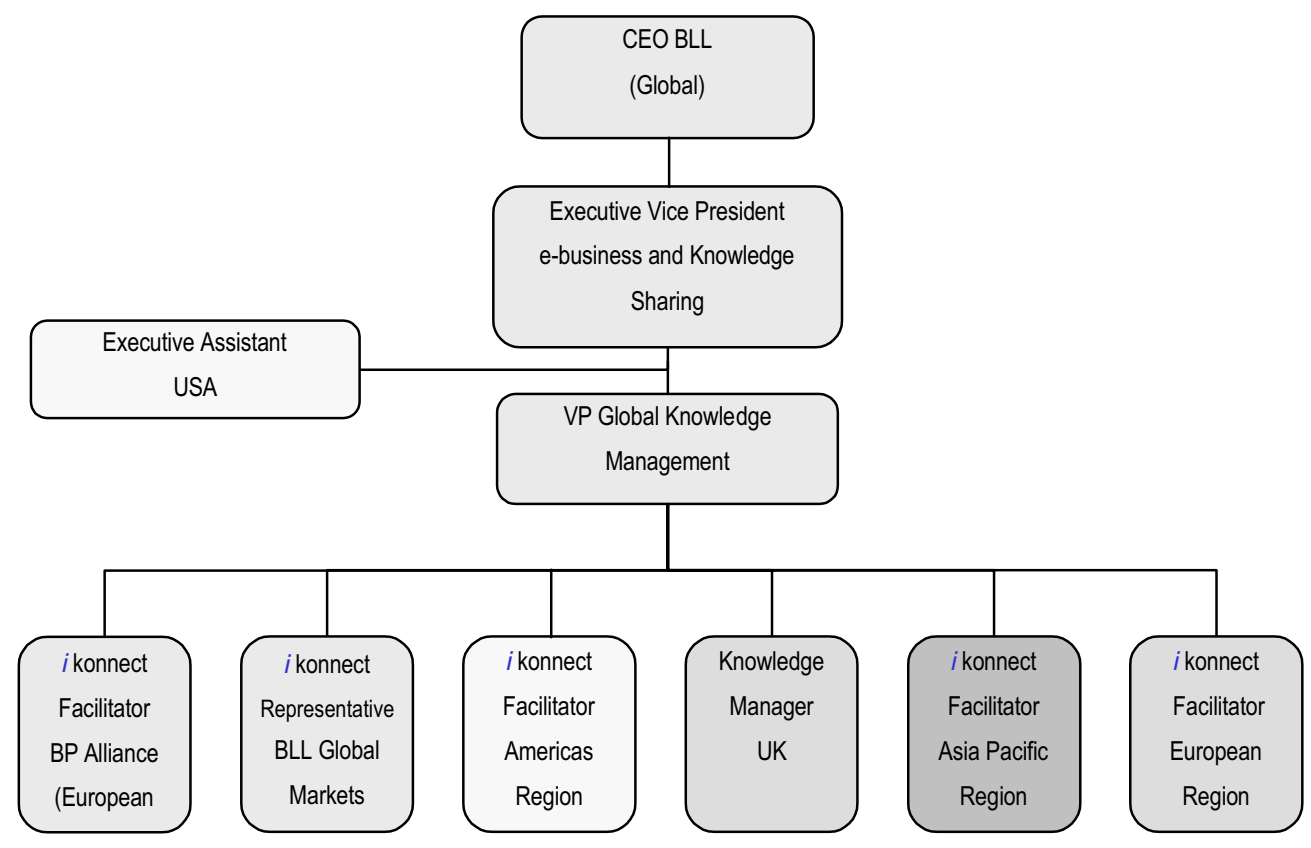

Figure 2: BLL's ikonnect ${ }^{\text {TM }}$ Global Team Structure (Source: BLL 2002) 
Such organisational structure is evidence of the top management commitment and support of ikonnect ${ }^{\mathrm{TM}} \mathrm{KM}$ activities. Furthermore, each of the top and selected middle management personnel were required to sign a performance agreement to participate in this KM initiative, which becomes part of the performance assessment criteria. The purpose of such an arrangement is to enhance the commitment of the management team in respect of the implementation of ikonnect ${ }^{\mathrm{TM}}$. With the commitment and self-experience of the middle management in ikonnect ${ }^{\mathrm{TM}} \mathrm{KM}$ activities, ikonnect ${ }^{\mathrm{TM}}$ would be easily implemented in all departments.

\section{Currently, the policies employed in BLL in knowledge} contributing and sharing are practised at senior management level in the company. All the senior managers worldwide have a "performance contract", in which they must have a target amount of ikonnect ${ }^{\mathrm{TM}}$ activities and when achieved, are rewarded with bonus at the end of the year. The financial rewards are only at the senior management level because of the "trickle down" effect on a large number of employees within individual management units. The volume of ikonnect ${ }^{\mathrm{TM}}$ activity of each senior manager is not measured on an individual basis but is the collective of activities of the whole business unit under their leadership. Thus, the usage of ikonnect ${ }^{\mathrm{TM}}$ in BLL depends on the initiative of the business unit leaders who are willing to participate in such activity. Reward practices are also aimed at empowering senior management by imbuing them with the objectives of $i k^{2}$ nnect ${ }^{\mathrm{TM}}$ rather than instructing them how and what to do with ikonnect ${ }^{\mathrm{TM}}$.

The key responsibility of ikonnect ${ }^{\mathrm{TM}}$ facilitators in each region is to run the ikonnect ${ }^{\mathrm{TM}}$ services within the company through the deployment of a corporate business "help desk". When the facilitators receive telephone calls or emails from their own region or other regions, they will help to find somebody within the company who could solve the problem and then get the questions and solutions together and build up such a database. Therefore, each of the ikonnect ${ }^{\mathrm{TM}}$ facilitators needs to have a very broad network skill and experience within the company in order to provide and allocate solutions to requests quickly. Besides running the ikonnect ${ }^{\mathrm{TM}}$ service, the facilitators are responsible for the development of the ikonnect ${ }^{\mathrm{TM}}$ system since they are directly in charge of the system. Their experience and understanding about the system provides them with the knowledge of how to further improve the system.

From the implementation of ikonnect ${ }^{\mathrm{TM}}$ in $\mathrm{BLL}$, it is clear that the company is now focusing in "know-who" knowledge (and tacit knowledge) as well as the flow of this knowledge. The company's key knowledge asset is, therefore, the personnel within the company. The claim has been made that $99 \%$ of their intellectual assets are kept inside their people's heads while only approximately $1 \%$ of their knowledge is housed in their databases. In order to find the knowledge in a person's head, the only way is through the direct conversation from person to person - which leads to the concept of ikonnect ${ }^{\mathrm{TM}}$ in BLL. There is no doubt that there are certain relationships between $\mathrm{KM}$ and a human resource management strategy since company personnel must be recognised as their main knowledge asset. However, BLL's KM is not focused only at human resources, but also, it aims at change management and employees' involvement. At the time of writing the paper, ikonnect ${ }^{\mathrm{TM}}$ is particularly focused at the change of senior management in the company.

According to BLL's knowledge project manager (KPM), there is a direct correlation between ikonnect ${ }^{\mathrm{TM}}$ and the company's innovation capacity. From the management's viewpoint, whenever there is a question being asked, the questioner obtains answers and can proceed with their work more effectively and efficiently. From the answers obtained through ikonnect ${ }^{\mathrm{TM}}$, employees manage to find different ways to solve their problems, thus indirectly broadening the employees' perceptions towards a problem and creating an "innovation" environment in BLL. Moreover, BLL's knowledge project manager claims that innovation within BLL would not occur and grow by itself without support from the KM system - ikonnect ${ }^{\mathrm{TM}}$. Technical Capability in Knowledge Management As ikonnect ${ }^{\mathrm{TM}}$ is implemented to increase the flow rate of knowledge within BLL, the KM infrastructures used are their employees and the existing information technology systems. The key intellectual asset in BLL is the knowledge of their personnel. The sharing and transferring of knowledge among the employees is a "people" activity, and is dependent upon their initiative and willingness. Therefore, the employees in BLL are being considered as the main KM infrastructure rather than their information technology. Having said this, technologies such as telephone, email, corporate intranet portal (called the "Hive"), and databases are used as a part of KM infrastructure, to support the ikonnect ${ }^{\mathrm{TM}}$ system.

ikonnect ${ }^{\mathrm{TM}}$ is a dynamic "just-in-time" KM system. Whenever questions are asked, the facilitators are responsible for capturing the questions, the person who asked the question (the "seeker"), the people who provided insights (the "sharer"), and the key insights. By doing so, knowledge that is potentially useful to the company is captured and stored in the database and if any other person asks the same question in the future, the facilitators can provide the answers easily or allocate the person who is able to answer the questions. Usually, the facilitators may get the questions and answers verbally (that is, sharing tacit knowledge between the two parties). They then encode the knowledge into a purpose-built and internet-enabled database that was built to capture the knowledge generated by ikonnect ${ }^{\mathrm{TM}}$ in the company. Besides, answers sometimes may be in the digital form such as a Word document, PowerPoint or Excel file. These documents and files are normally attached to the questions in the database and stored in the servers. Currently, the ikonnect ${ }^{\mathrm{TM}}$ database is still in a facilitator-aided services stage but will be made available next year to every employee in the company. By that time, all employees in BLL will be able to make their own search on the questions-andanswers database to retrieve, share and use the knowledge within the company.

The use and reuse of a person's knowledge in BLL through ikonnect ${ }^{\mathrm{TM}}$ is basically taking implicit (tacit) knowledge (inside a human's head) and converting it mostly into explicit knowledge. This is because tacit knowledge is still very hard to share due to the knowledge-learning nature of tacit knowledge, such as 
muscular skills that require self-experience in order to understand and use it. The conversion of the knowledge enables learning among their employees. However, challenges exist and have been identified in two important steps: getting people to ask questions and getting people to use or seek answers. It is not easy to ensure that everyone will use the answers they obtained from the ikonnect ${ }^{\mathrm{TM}}$ system. An assumption is made that whenever somebody takes the time and initiative to ask a question, it is very likely that the person will use the answers provided as the driving force, given that asking questions of the system is a voluntary activity.

Knowledge retrieval in BLL is the main responsibility of the ikonnect ${ }^{\mathrm{TM}}$ facilitators. When they look for somebody who can answer the questions, they are undertaking a knowledge retrieval function. Usually, the retrieving of knowledge workers within BLL is carried out by the facilitators through their experiences, skills as well as the networks and use of company databases, such as ikonnect ${ }^{\mathrm{TM}}$ database, Boomerang, Merlin, Project Web and "BDWeb" (Business-Development Web). When the person who can provide an answer to the seeker is found, ikonnect ${ }^{\mathrm{TM}}$ facilitators will bring both persons (sometimes more than two) to connect together through conversation or email. From the connections, knowledge has been retrieved and shared within the company.

Knowledge Management Performance Assessment BLL invested approximately $A \$ 5$ million during the 18 monthperiod of the implementation of ikonnect ${ }^{\mathrm{TM}}$ in the company. The annual budget for KM programs in BLL is approximately $A \$ 2.5$ million globally and approximately $\mathrm{A} \$ 0.3$ million for the AsiaPacific region. One of the perceived benefits of this KM system has been the desired improvement of increasing the inquisitive behaviour of employees in BLL as the ikonnect ${ }^{\mathrm{TM}}$ system encourages employees to ask questions. When the employees are more inquisitive, they will be more innovative; tasks will be completed quickly and efficiently, as solutions to a problem can be obtained quickly through the KM system. According to the KPM in BLL, the impact has been estimated to be about $10 \%$ of the business performance. This measure is derived from the usage capacity globally, which at the moment, is approximately 700 employees (about 10\% of total employment).

However, the impact from ikonnect ${ }^{\mathrm{TM}}$ in BLL has been significant despite the fact that they are still not able to easily measure the tangible economic benefits gained from these ${ }^{i k o n n e c t}{ }^{\mathrm{TM}}$ activities, and if the financial benefit is to be measured, there will be many other factors involved. Although the link between the usages and benefits of ikonnect ${ }^{\mathrm{TM}}$ is not yet established or clearly understood, they believe that as the usage increases, the benefits gained will also increase. Factors Influencing Knowledge Management Implementation The knowledge officer of BLL claims that the ikonnect ${ }^{\mathrm{TM}}$ system is about changing the behaviour of the employees in BLL. Changing human behaviour is the most difficult task because if someone is doing a job in certain ways that he/she is already used to, he/she will be resistant to a new way of working. With more than 7,000 employees in the company, the collective behaviour from different employees with different backgrounds and cultures is thus the key factor influencing the implementation of KM in BLL.

The KM strategy used in BLL is more towards change management, where KM is considered as the method used to change employees' behaviour. The measurement of ikonnect ${ }^{\mathrm{TM}}$ capacity and rewards and recognitions programs are all designed to change employees' behaviour. Communication tools such as corporate intranet (the "Hive") are used to publish newsletters about the ikonnect ${ }^{\mathrm{TM}}$ activities executed throughout the company.

To overcome the difficulties of the cultural issue in the company, most of the approaches used are actually trial and error approaches. If an approach works, then the KM strategy used will be continued; otherwise, it will be aborted. The cultural issue is a very situation-specific issue in BLL as the company has its businesses throughout the world. They have not adopted any classical approaches from those advocated in KM literature as a ready-made solution to their own uniquely challenging KM situation.

The knowledge project manager has provided the following generalised recommendations for implementing KM in construction companies:

- Construction companies need to be aware of their cultural strengths and weaknesses before implementing KM in their company.

- The KM strategy in the company should support and help to achieve the company vision, mission and objectives.

- KM implementation should obtain clear sponsorship from top management.

- KM should focus on the challenge of knowledge flow rather than creating knowledge databases since knowledge stored in the databases is static.

\section{CASE 2 - LEIGHTON CONTRACTORS Pty LIMITED (LCPL)}

Company Background and Infrastructures in Relation to KM LCPL is a major subsidiary company of Leighton Holdings Limited, which was originally founded in Victoria Australia in1949 and has grown from a small engineering firm into a diversified organisation. Today, LCPL is an experienced project developer and construction contractor in Australia. With over 2000 employees, the company is involved in large-scale complex projects, including telecommunications, land transport, building, civil and process engineering, and contract mining in Australia. (LCPL, 2004).

LCPL started its in-house computer-based systems in the late 1960s / early 1970's for business and system development. Computers were used for preparation of tenders, financial and commercial systems, quality control, environmental control as well as health and safety management. KM was initiated in LCPL in early 1998 by the company's Chief Knowledge Officer (CKO). LCPL's approach to implementing KM is based on commercial imperatives. The construction industry is becoming more complex, and this has led to more sophisticated 
documentation and information management within the company's business processes, particularly in managing construction projects. Moreover, the tendering process is very cost intensive and, as a contractor, LCPL are now required to take on more risk and needs to complete complex projects in tight timeframes. Therefore, LCPL's approach to implementing $\mathrm{KM}$ has been to view KM as a process of capturing information and knowledge acquired from previous projects and making this knowledge available to employees in the company. Currently, LCPL is particularly focused on leveraging and transferring the knowledge learnt in order to improve the company's business processes.

\section{Knowledge Management Perspectives}

In LCPL, the KM department has two main objectives: to provide increased competitive advantage by leveraging company corporate memory and lessons learnt, and to increase company stocks of intangible assets and leverage their value. In order to achieve these KM objectives, LCPL has set some long-term strategic plans to ensure the company progresses towards the target. Initially, LCPL's KM focus is on delivery of product and service, improving business processes - these include enhancing communication by using new and different information technology (IT) systems, such as collaborative computing with external suppliers. The company is also progressively re-engineering their management processes and business rules to increase operational efficiency and to improve the connection and collaboration with internal and external stakeholders. Besides that, they also put special consideration in changing the workplace into a "knowledge sharing place" by using KM as the vehicle (see Figure 3).

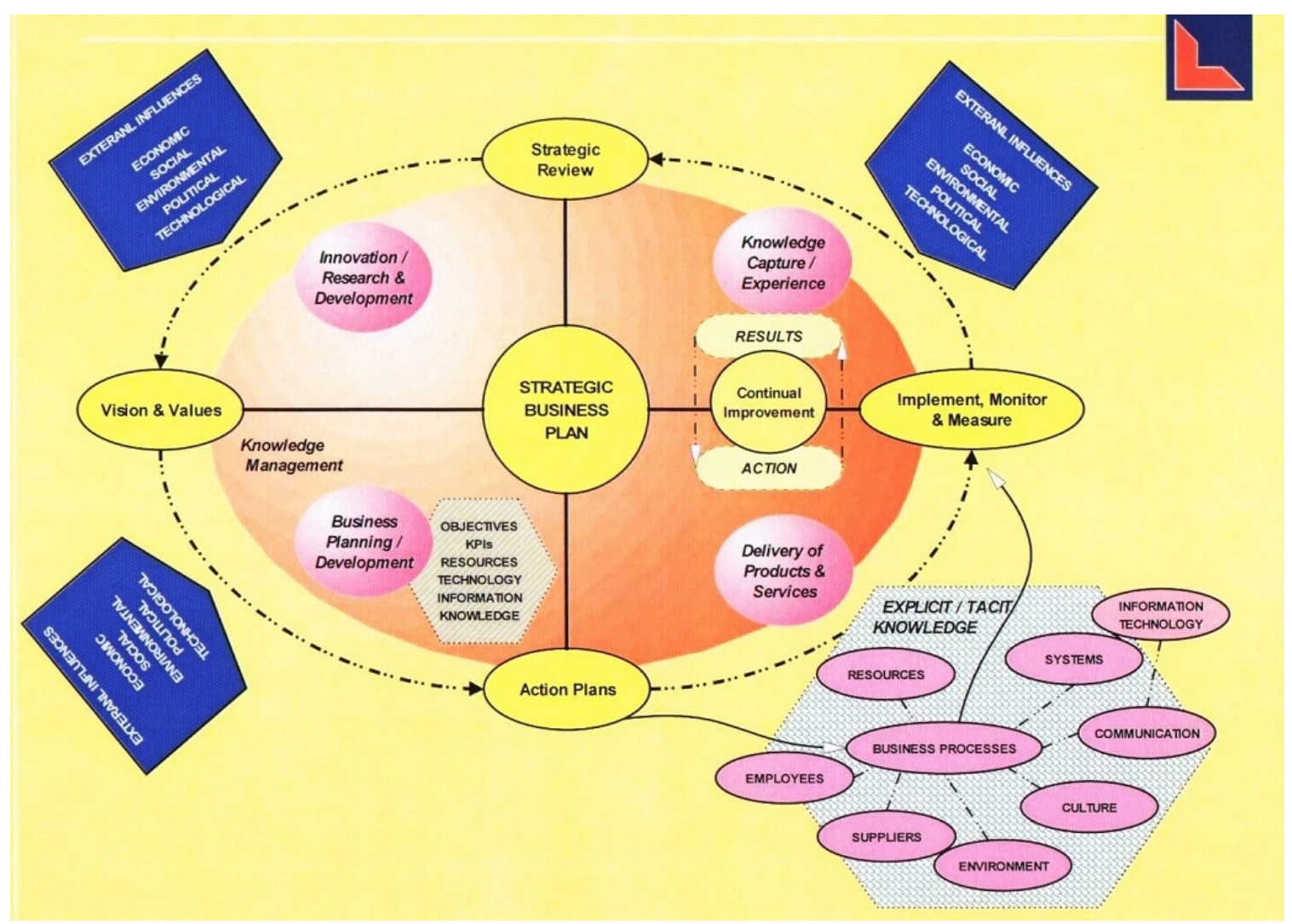

Figure 3: LCPL's knowledge strategy - future focus on using KM to change the culture to a knowledge sharing environment (Source: LCPL 2002)

\section{Knowledge Management Processes}

The KM organisational structure in LCPC is shown in Figure 4. It is clear that the CKO is one of the senior management role in the company. The CKO in LCPL is basically responsible for the operation of corporate KM activities which are divided into four departments. These departments act collaboratively to support the company's KM infrastructure, namely - Electronic Document Management System (EDMS) and corporate library. Under the CKO, there is a technical consultant group that provides IT support, a business analysis group that studies the company's requirements and needs in order to embed the
EDMS into the company's business processes, and a training group that provides training of employees in the use of the EDMS. There is a corporate library that provides useful learning resources and facilities for employees to search and learn from both hard copy documents and online electronic reference materials. 


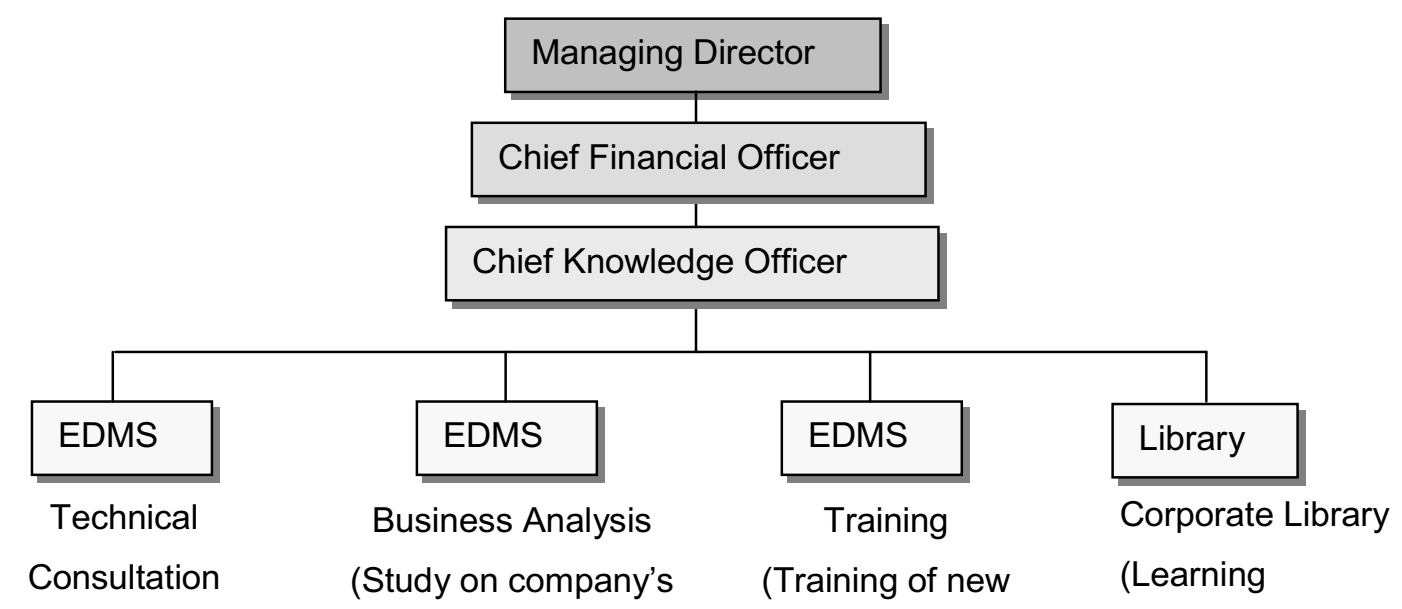

Figure 4: KM organisational structure in LCPL showing the position of the CKO (Source: LCPL, 2002)

LCPL has categorised their knowledge assets as explicit and tacit knowledge which forms the company's intangible assets. Explicit knowledge includes hardcopy and electronic documentation comprising corporate systems, processes and experience, whilst tacit knowledge is held by its personnel in the form of personal experience, skills, and collaboration within workgroups. These intangible assets in LCPL help to enhance its existing business processes and increase the level of acceptance and commitment to KM implementation.

In order to develop and improve the innovation capacity, the KM Department in LCPL has placed considerable emphasis on improving the process of understanding client and project's needs. This led in turn to a focus on developing KM systems and applications based on user feedback and project needs including leveraging corporate knowledge through distribution of knowledge via the EDMS, intranet, website, etc.

Technical Capability in Knowledge Management As a leading construction company, LCPL deals with extremely large quantities of information and documents in its business operations. The knowledge infrastructure systems used in LCPL include:

EDMS (Electronic Document Management System) information is captured in digital format and shared online throughout the project. This leads to the standardisation of processes to manage information of a project.

LCPL Computer Network - this is quite a sophisticated network which includes a wide area network (WAN) and links up every individual construction project across Australia.

LCPL Intranet - a centre portal provides access to various business applications thereby internalizing the company's intellectual assets.

- LCPL Management Systems - this includes its business management systems, administration systems, human resource management systems, project management systems, etc by providing online access to procedures, forms, project plans etc. and is used throughout the company in its Branches and projects.
Corporate library - including online National Standards and other reference materials such as access to legislation, financial reports of other companies, Building Codes, Business Who's Who, etc. This library also stores the learning resources that were derived from passed experience gained during the construction of projects. Skilled personnel - the knowledge workers.

Basically, LCPL captures and stores knowledge using EDMS, LCPL network and applications as well as in hard copies. As a standard process in the company, project information is captured through EDMS or file/print servers, then archived into the central library. Every construction project procured by the company has its own EDMS that provides the basis for standardisation of business processes, formalising the capture of all knowledge for future learning.

After the knowledge has been captured, company employees are able to explore and use the knowledge, especially various project scenarios that have been experienced by the company throughout the country. Generally, the "use" of knowledge in LCPL has been towards tacit knowledge held in the heads of employees, but as the EDMS being deployed, the knowledge utilisation is becoming more explicit as most of the knowledge is in digital format with access via the company computer network and related applications.

To assist company personnel to contact other personnel within the company there is a phone list directory on the company intranet which includes particulars of all staff. The retrieval of the company personnel particulars can be interrogated by either the location or project. Currently (at the time of writing the paper), the personnel particulars directory is still relatively simple but will be extended in the near future.

Apart from the company network systems, informal communication network among employees in the same office, via mechanisms such as corridor conversation, is also a regular means of knowledge sharing in LCPL.

Knowledge Management Performance Assessment After 5 years of KM implementation with an annual budget of 
approximately AUD $\$ 2.5$ million the company attempted to assess their KM performance by using qualitative key performance indicators (KPI) such as feedback from users, improvements in efficiency and the number of people required to manage documents/information. In relation to the performance assessment, some tangible benefits gained by LCPL after implementing KM include:

\section{Better business processes}

Increase standardization

Less reinventing the wheel

Better access to information

Increase skill in how to leverage knowledge.

LCPL claims that it is still too early to measure the effectiveness of KM since the KM system needs to be properly established and be consistent before assessment is started. Furthermore, under any situation, it is difficult to do so since the performance of the business operations is influenced by many factors (such as people, resources, strategies and project management) rather than just the KM implementation.

Factors Influencing Knowledge Management Implementation $\mathrm{KM}$ implementation in LCPL is influenced by various factors and the most significant being the cultural factor. Culture of a company very much depends on the attitude of people who work in the company. From the KM Department's viewpoint, cultural issues could be improved by improving communication between the management and the employees. The involvement of employees in the company's KM system is highly encouraged. The KM Department uses feedback from the employees to assist the improvement of the company's business processes. Moreover, the engagement of stakeholders to own the KM process is promoted by LCPL in order to further modify cultural change to a more knowledgesharing environment.

The LCPL's CKO provides the following suggestions for the implementation of KM in a construction company:

Patience and get endorsement from the top management (usually indicated by allocation of budget and resources). Persistence with vision and creating products/services that assists the business to operate more efficiently and effectively.

Work on improving corporate memory and provide access for others to benefit.

Make it easy for employees to find and use information and knowledge.

Build culture of knowledge transfer, sharing and learning.

\section{COMMENTS AND DISCUSSIONS}

Both companies studied are Australian construction companies that operate on a national and international arena and are pioneers in KM. The large number of employees in both companies is a typical issue in terms of KM as a KM system has to be designed that will fit all employees in the company in order to effectively leverage on their intellectual assets for sustainable improvement in their business operations. Employees' knowledge within the company cannot be transferred from one person to another without a proper KM system. With large numbers of employees, and the geographical barriers for employees' knowledge sharing, how these companies implemented KM is an important area for the research.

\section{Knowledge Management Perspectives}

Both companies are implementing KM in alignment with their companies' business visions and strategies. This matches the KM implementation principles suggested by Tiwana (2000) that KM should clearly articulate a link with corporate business strategy. Only with such alignment between KM and business strategy, can a company be sure that the KM system is moving in the direction that holds promise for sustainable competitive advantage and benefit to both company's employees and company business operations (Tiwana, 2000).

BLL is more concerned about the knowledge-sharing among their employees and they view knowledge as a "dynamic" entity"; therefore they have shifted their KM strategy from a "static" implementation - viz. technological facilities and knowledge databases - to a "dynamic" implementation through the deployment of the ikonnect ${ }^{\mathrm{TM}}$ program, which encourages the culture of knowledge sharing within the company. LCPL implements KM through the deployment of knowledge infrastructures and EDMS which is aligned with their company's business needs and requirements. The company has a longterm strategy in developing the KM system and incorporating this with the business/planning development, delivery of products and services, innovation and research and development, and knowledge and experience captured, to create a knowledge-sharing environment within the company in the future.

It is clear that the two companies have different KM implementation strategies. LCPL is more technological focused, and utilizes advances in information technologies to facilitate knowledge capturing, sharing, utilising and retrieving while BLL is more people-focused, in that personal knowledge-sharing is encouraged and operated via simple communication tools. In BLL, the key knowledge asset was seen to be the company's personnel who have knowledge stored in their brain while company databases only formed a minor part in their knowledge assets. LCPL categorized their knowledge assets into explicit and tacit, and equally weighted both technological infrastructures and employees' knowledge as their knowledge asset. Gann (2000) stated that tacit knowledge is more valuable than explicit knowledge and it is a key part of knowledge creation in a construction company. People will continue to be the source of tacit knowledge and thus people will be pivotal in the creation of valuable knowledge.

\section{Knowledge Management Processes}

Both companies have established their KM team in response to their KM systems' needs while balancing the technical and managerial requirements. Both companies believe that their KM systems are able to improve their innovative capabilities and therefore they have devoted considerable resources in developing their KM systems. Both companies have similar organisational structures that reflect the top management commitment and leadership, to address the KM implementation. BLL's management considers that the ikonnect ${ }^{\mathrm{TM}}$ program has 
enhanced their innovative capabilities since employees appear to improve their decision-making and problem-solving when they ask a question through the ikonnect ${ }^{\mathrm{TM}}$ system.

Due to the fact that the KM system is focused on people, BLL has established a reward and recognition system to motivate the employees to use the KM system. BLL established a fulltime team to facilitate knowledge sharing and the management has put considerable effort into the measurement of ikonnect ${ }^{\mathrm{TM}}$ usage. In contrast, in order to improve their innovative capabilities, the KM department of LCPL places emphasis on developing the knowledge systems (EDMS) based on feedback and understanding of clients' and projects' needs. The KM system in LCPL is focused more on technology and thus they have less emphasis on establishing new policies to motivate people. It is the writers' view that in order to effectively implement KM, an appropriate motivation system is essential to develop a convivial culture within which employees are prepared to exploit the new KM system.

Technical Capability in Knowledge Management

Both BLL and LCPL have placed different emphases on KM infrastructures and their individual in-house KM structures are tailored for their KM requirements. LCPL has a KM structure that focuses mainly on support of their key KM system (EDMS) in order to operate the system effectively and efficiently. On the other hand, BLL claimed that their KM infrastructure is their people, rather than technologies and they are implementing a very people-focused KM system - every task in capturing, retrieving, storing, using, and sharing knowledge is done by people. In BLL, technologies that facilitate the processes are considered as a secondary means in their KM system. (it should be pointed out BLL in fact also has a comprehensive KM infrastructure including hardware and software programs). On the other hand, KM in LCPL largely relies on their technological infrastructures and information systems (e.g. EDMS) and applications were established to facilitate their KM processes. This shows that the selection of knowledge infrastructures should be complementary to the KM system designed besides profiling a mechanism for push and pull knowledge delivery within a company (Tiwana, 2000).

Knowledge Management Performance Assessment In order to gain commitment from top management, an appropriate KM performance measurement system can help to prove the impact of effective KM and enable the refinement of KM design through subsequent iterations (Tiwana, 2000). KM strategy must be linked to performance measurement which needs to show explicit value, rather than being generally "good for the company" (Metes, et al, 1998). Therefore, the performance measurement should account for both financial and competitive impacts of KM in the company's business. Both companies claimed that the implementation of KM has helped improving their business processes, competitiveness, decisionmaking and problem solving and, by progressively developing the system, they believed that their companies will gain financial returns in the future.

$\mathrm{KM}$ performance assessment is a critical issue in both companies. People expect to obtain benefits from efforts they put into the work. It is unrealistic to expect employees to commit to a system or process if the efforts are not rewarded by commensurate benefits. Hence, KM performance assessment is essential in measuring the effectiveness of a system to establish whether the objectives are appropriately formulated, and whether KM activities are being carried out successfully (Probst et al., 2000). Certainly, benefits do not happen overnight and the time needed to receive tangible and intangible benefits from KM, particularly in respect to cultural and attitude changes, should not be underestimated. Some measures of the impact that KM brings about (as KM performance assessment) could be: shortened project time, improved project quality and reduced project cost and value-added to business/product.

Factors Influencing Knowledge Management Implementation $\mathrm{KM}$ implementation is influenced by many factors, including culture, people, technology and processes (Zou et al., 2003), and the most significant factor that influences the KM implementation in BLL and LCPL is the cultural issue. Both companies are working very hard to identify solutions for overcoming the cultural issues in KM implementation and they have laid particular emphasis on fostering a knowledge-sharing culture and the management of such a cultural change. Egbu et al (2004: 18) also stated that "individuals are important sources of tacit knowledge" but "changing people's behaviour is the biggest impediment to knowledge transfer within organizations". Cultural issues involving human behaviour, attitudes, thoughts and relationships can lead to resistance to changes in their working environment. New working methods imply that employees have to shift out of their comfort zone and employees are afraid that their benefits would be challenged (Naoum, 2001). Moreover, the commitment and trust between human to human and human to technologies/systems added to the barriers. KM largely relies on knowledge flow, while knowledge flow is based on the willingness of knowledge sharing. Nevertheless, effective knowledge-sharing requires trust, but it is difficult to create (Probst et al., 2000). KM, therefore, should not only be focused solely on technological development but also on an appropriate cultural development in the organization. Both companies' managements realized this behavioural and cultural problem and therefore focused on the people and culture issues rather than technological issues. Both BLL and LCPL understand that the databases, which contain "static" knowledge", could not improve the knowledge flow within the company, since no matter how good the technology may be, it will exist in name only if people are not using it (Malhotra, 2000). In comparison of the two companies in relation to KM implementation, it appears that BLL has moved from a technology focus to people focus approach while Leighton may emphasis more on technology aspect of KM.

Another important issue derived from these two cases studied is the top management's commitment to KM implementation. In order to obtain support from top management, KM implementation requires an appropriate performance assessment system, which allows top management to see the benefits generated from KM implementation. 
After a compressive review of the literature, two cases were studied in the form of desktop study and semi-structured interviews to investigate the KM implementation in construction companies. Based on the research findings, the following conclusions can be made:

- The implementation of KM improves capabilities in competition, decision-making, problem-solving and innovation.

The implementation of KM in construction companies should be linked to corporate business visions and strategies.

Proper organisational structure in relation to $\mathrm{KM}$ is necessary and should be established according to its KM vision and strategies, and as a reflection of top management commitment and leadership.

Merely capturing knowledge in an explicit form and storing it in the company's database does not necessarily help improve the company's competitiveness or decisionmaking: it is the "people" that makes it work and a culture of learning, sharing and using knowledge is essential. This means that while technology plays an important role in KM, "people" are still the key to successful KM implementation. KM implementation is influenced significantly by organisational cultural factors. A knowledge-sharing organizational culture must be developed. This suggests that KM implementation in construction companies should be focused in the development of an appropriate culture at the organisational level in combination with information and communication technological development.

Change management should be in place when implementing KM, to help to change employees' attitudes and behaviour in relation to knowledge- learning, -sharing and -applying.

Although both companies believed that the implementation of KM has improved their business processes, they were still in their infancy in assessing the performance from their KM system. This finding prompts the need for an appropriate KM performance assessment method in which the measure may not purely be in monetary terms but other value-added terms

One size does not fit all -- no one KM strategy will suit every company. Different companies should have different KM strategies that fit in to the companies' vision. In the cases studied, BLL is focused in enhancing knowledge-sharing through the deployment of the ikonnect ${ }^{\mathrm{TM}}$ program while LCPL is focused in developing a knowledge environment through the implementation of EDMS and the corporate library.

In short, the implementation of KM should incorporate a company's vision, work processes, technology and culture, to support and improve the ability of construction companies in knowledge creating, capturing, transferring, sharing and retrieving and, ultimately, to improve the company's competitive advantage, decision-making, problem solving and innovation capabilities. However no one KM strategy will suit every company and people and culture are still the keys to successful $\mathrm{KM}$ while technology acts as an enabler.
Last but not least, it should be pointed out that this paper has only conducted study with two leading AEC firms in Australia, more studies should be conducted to allow a more comprehensive conclusion to be made. As such it is suggested that further studies be conducted with more companies particularly the small and medium sized construction companies and a framework be developed for these companies.

\section{ACKNOWLEDGEMENT}

The author would like to thank Mr. Garry Cullen of Bovis Lend Lease Australia and Mr. Duncan Robinson of Leighton Contractors Pty Limited Australia for providing invaluable information and comments on this paper.

The author would also like to thank Professor Denny McGeorge for his invaluable comments and Chie-Ann Lim for his assistance in producing this paper.

\section{REFERENCES}

BLL (Bovis Lend Lease) (2002a), Frequently asked questions, internal document.

BLL (Bovis Lend Lease) (2002b), ikonnect ${ }^{\mathrm{TM}}$ briefing letter, internal document.

BLL (Bovis Lend Lease) (2002c), ikonnect ${ }^{\mathrm{TM}}$ Newsletter, internal document.

BLL (Bovis Lend Lease) (2002d), ikonnect ${ }^{\mathrm{TM}}$ prompt sheet, internal document.

BLL (Bovis Lend Lease) (2002e), Interview with the CEO, video- $C D$, internal document.

BLL (Bovis Lend Lease) (2004a), company homepage website: www.bovislendlease.com.au.

BLL (Bovis Lend Lease), (2004b), company homepage containing the ikonnect program information, website: http:// ikonnect.lendlease.com.

Chang C.H., Lin Y.C. and Tserng H.P. (2003), The application of knowledge management in Taiwan public construction projects, Proceedings of the joint international symposium of CIB Working Commissions W55, W65 and W107, "knowledge construction", Ofori G and Ling F.Y.Y. (editors), Singapore, 2224 Oct 2003, Vol 1, p76-86.

Egbu C.O. (1999), Skills, knowledge and competencies for managing construction refurbishment works, Construction Management and Economics, Vol 17, pp 29-43.

Egbu C., Hayles C., Quintas P., Hutchinson V., Anumba C. and Ruikar K. (2004), Knowledge management for sustainable construction competitiveness, final report July 2004, available on website: http://www.knowledgemanagement.uk.net), accessed on 22 Sept 2004

Fong P.S.W. (2003), Managing Knowledge: A Critical Investigation of workplace learning, Proceedings of CIB W89 International Conference on Building Education and Research, (BEAR 2003), Newton R., Bowden A and Betts M (editors), p1143 - 1156 . 
Gann, D.M. (2000), Building Innovation: Complex Constructions in a Changing World, Thomas Telford Publishing, London.

Girmscheid G. and Borner R. (2003), Knowledge management in construction companies oriented on project success factors, Proceedings of the joint international symposium of CIB Working Commissions W55, W65 and W107, "knowledge construction", Ofori G and Ling F.Y.Y. (editors), Singapore, 2224 Oct 2003, Vol 1, $137-149$.

Johnson B. and Christensen L., (2000), Educational Research: Quantitative and Qualitative Approaches, Allyn and Bacon, MA 02494.

Kamara J.M., Anumba C.J. and Carrillo P.M. (2002), A CLEAR approach to selecting a knowledge management strategy, International Journal of Project Management, Vol 20 (2002) pp $205-211$.

Kliem R.L. (1999) The role of project management in knowledge management, in Information management, strategy, systems and technology, Auerbach Publications 1999 CRC Press Aug 1999.

LCPL (Leighton Contractors Pty Limited), (2002), Strategic plan in knowledge management, internal document.

LCPL (Leighton Contractors Pty Limited), (2004), company homepage website: www.leightoncontractors.com.au.

Malhotra, Y. (2000), "Knowledge Management for E-Business Performance: Advancing Information Strategy to Internet Time", available at <http://km. brint.com> or <http://www.kmbook.com>, [accessed March 2002]. Published in Information Strategy: The Executive's Journal, vol. 16(4), 2000, pp. 5-16.

Naoum, S. (2001), People and Organisational Management in Construction, Thomas Telford Publishing Ltd., USA.

Ofori G. (2003), Preparing Singapore's construction industry for the knowledge-based economy: practices, procedures and performance, Construction Management and Economics Vol 21 pp $113-125$.

Probst G., Raub S. and Romhardt K., (2000), Managing Knowledge - Building Blocks for Success, John Wiley and Son Ltd. England.

Rezgui Y. (2001) "Review of information and the state of the art of knowledge management practices in the construction industry", The Knowledge Engineering Review, Vol. 16 (3), pp 241-254.

Siemieniuch C.E. and Sinclair M.A. (2004) "A framework for organisational readiness for knowledge management" International of Operations and Productions Management, Vol 24 No. 1, pp 79-98.

Tiwana, A. (2000), The Knowledge Management Toolkit Practical Techniques for Building a Knowledge Management System, Prentice-Hall, Inc., New Jersey, USA.

Zou P.X.W. and Lim C.A. (2002), "The implementation of knowledge management and organisational learning in construction management", Proceeding of International conference on advances in buildings technologies (ABT2002), 4-6 Dec 2002, Hong Kong, Vol 2., pp1745-1753.
Zou P.X.W., McGeorge D. and Lim C.A. (2003), "Implementing knowledge management in construction companies - why is it necessary?" Proceedings of Joint International Symposium of CIB Working Commissions W55, W65 and W107 "Knowledge construction" (Ofori G and Lin YY (editors)), Singapore 23 - 24 Oct 2003, Vol. 1, p251-264. 
